\title{
TECHNOLOGICAL MODEL AND SUSTAINABILITY ASSESSMENT METHODOLOGY OF THE MULTISERVICE COMMUNICATION NETWORK FUNCTIONING
}

\section{Viktor N. Kudelya,}

Institute for Networking Technology, Saint-Petersburg, Russia, Kudelia.Viktor@int.spb.ru

Valentine E. Gel, Military Academy of Communications, Saint-Petersburg, Russia, gel@rambler.ru

Valeriy V. Vovk, General Directorate of communications, Moscow, Russia, GUS_I@mil.ru
Manuscript received 16 February 2021; Accepted 22 March 2021

Keywords: network, resilience, stability of functioning, quality of service

\begin{abstract}
The modern development of multiservice communication networks (MCN) is characterized by the desire of operators to provide users with an unlimited range of services with guaranteed quality of service (QoS). QoS is determined by the stability of the network's functioning, that is, its ability to function without errors. The existing routing algorithms in modern networks focus the main load on the most productive sections, while the rest of the network is used quite poorly. This is confirmed by the results of studies $[1,2]$, in which the structure of modern global communication networks is assigned to the class of small-world graphs. Obviously, that the increased connectivity of such networks determines high indicators of its stability, but at the same time, this route redundancy is poorly used by existing routing protocols to provide QoS when transmitting different traffic (triple-play: audio, video, and data) [3, 4]. There is also no work devoted to the analysis of the possibilities of sharing different routes (route parallelism) for the implementation of QoS enhancement mechanisms in the MCN. This article discusses the technological concept of a network with route parallelism in communication networks built on the basis of the IP protocol family.
\end{abstract}

Information about authors:

Viktor N. Kudelya, leading specialist, Dr., Institute for Networking Technology, Saint-Petersburg, Russia

Valentine E. Gel, candidate of military sciences, associate professor, Military Academy of Communications, Saint-Petersburg, Russia Valeriy V. Vovk, head of the department,General Directorate of communications, Moscow, Russia

Для цитирования:

Куделя В.Н., Гель В.Э., Вовк В.В. Технологическая модель и методика оценки устойчивости функционирования мультисервисной сети связи // Т-Сomm: Телекоммуникации и транспорт. 202I. Том I5. №6. С. 70-74.

For citation:

Kudelya V.N., Gel V.E., Vovk V.V. (202I)Technological model and sustainability assessment methodology of the multiservice communication network functioning. T-Comm, vol. 15, no.6, Pp. 70-74. (in Russian) 


\section{Mathematical model of the structure of a multiservice communication network with route parallelism}

In general, the MCN model can be formally represented as follows.

All $n$ objects ( $n=|N|$ - the capacity of the set of network nodes $N$ ), participating in the data exchange are numbered in a certain sequence, and the object with the number $i$ in the model is assigned a node $n_{i}$ regardless of the functions of this object in the exchange of information.

Some nodes of the model are connected by edges in pairs. Model edge connecting nodes $n_{i}$ and $n_{j}$ we will denote (ij). The set of edges will be denoted by the symbol $A$.

Interaction of the data entry point $C_{i}$ with the exit point $C_{j}$, ( $i, j=1,2, \ldots, c, c=|C|$ - power of multiple network nodes $C$ ) within the $\mathrm{MCN}$, performed through intermediate nodes $h_{k}$ ( $k=1,2, \ldots, h, h=|H|$ - power of multiple network nodes $H$ ) using IP packet switching. The route in the MCN includes nodes $C_{i}, C_{j}$ and some set of transit nodes $h_{k}$ between the sender and the recipient of the information.

In general, the MCN model can be represented as consisting of three components: a nodal basis, a network of edges (arcs), and an action technology.

A list of data that defines the model.

Parameters of the nodal basis. The set of nodes $N=\left\{n_{i}\right\}$; $i=1,2, \ldots,|N|$ - the set of natural numbers. The model node represents the entire set of devices located in the object being modeled. The node $n_{i}$ is characterized by the performance and probabilistic characteristics of packet processing. There are three types of nodes:

- $\quad$ boundary nodes $C_{i}, c_{i} \in C, i=1,2, \ldots,|C|$. The set $C_{i}$ forms the MCN boundary level;

- $\quad$ core nodes $h_{i}, h_{i} \in H, i=1,2, \ldots,|H|$. The set $h_{i}$ forms the core of the $\mathrm{MCN}$;

- $\quad$ center nodes $Z_{i}, Z_{i} \in Z, i=1,2, \ldots,|Z|, Z=|Z|$. The set

$Z_{i}$ forms the level of the MCN center.

Then $N=C \bigcup H \bigcup Z$.

Edge parameters. Edge $(i j) \in A$ it is characterized by its throughput and probabilistic characteristics of packet delivery. The probabilistic characteristics of the packet delivery of each edge is determined by the joint probability of delivery of the entire set of devices represented by it. MCN.

The set of these nodes and edges defines the structure of the

\section{Action technology.}

The node (nodes) of the center forms route subsystems on the set of MCN nodes $c_{i} \rightarrow c_{j}, i, j=1,2, \ldots, c-1$ - some finite set of routes for each pair of boundary nodes $C_{i}$ and $C_{j}$. Packet streams from $C_{i}$ in $C_{j}$ are distributed within the subsystem, between its routes. The formation of subsystems for each pair of boundary nodes and the algorithm for distributing flows between routes (route parallelism technology) in the subsystem are determined by the flow distribution plan for each type of traffic.

\section{The technology of route parallelism.}

The technology of route parallelism refers to packet switching technologies and involves the exchange of data between the sender and the receiver over several MCN routes.

The main functional and structural units of the MCN are nodes that perform the functions of processing, routing, packet communication and communication resources (channels, paths, networks). Communication resources are virtualized and, based on this, the MCN is based on the following principles of route parallelism:

- virtualization of the network topology, in which arbitrary routing can be implemented, while communication resources continue to function according to traditional protocols, for example, routing packets along a single shortest path;

- $\quad$ the parallelism of the existence of delivery routes (route subsystem) between a certain pair of nodes, i.e. the ability of several or all nodes to jointly and simultaneously solve the problem of parallel delivery of the packet flow between the source and the consumer;

- the prevailing use of mass (minimally complex) hardware and software and existing network equipment.

For each pair of nodes of some selected subset $C$ from the set $N$ all nodes of the MCN are formed on the set of $C \bigcup H$ set of routes. A set of routes contains more than one route. Such a set of routes will be called a route subsystem $C_{i} \rightarrow C_{j}$, where $c_{i}, c_{j} \in C$. The route subsystem is designed to implement route parallelism in the MCN. Packet flows between pairs of nodes from a subset $C$ are distributed within the subsystem between its routes.

The route from the route subsystem is entered in the service field of the packet (routing from the source) and is necessarily written in each packet that makes up the message (stream). A route from a route subsystem always starts at a node $C_{i}$ and ends at the node $C_{j}$ from the set $C$. Between nodes $C_{i}$ and $C_{j}$ a route can contain a number of transit nodes $h_{k}$ from the subset $H$. The subset $H$ is not an empty set. The route in the service field of the package is used as a pointer when selected in a node from a subset $H$ an address of the next $\mathrm{MCN}$ node to forward the packet. Prepare the process of developing route subsystems for the corresponding multiroute protocol. Using this protocol in a node from a subset of $Z \in N$ for each node from the subset $C$ a «tree» of route subsystems in the MCN is created between this node and all other nodes from the subset $C$.

\section{Model of the delay reduction mechanism}

Parallelization of information delivery has been known for a long time and is currently actively used in the transmission of information through various communication channels, including to reduce the time of information delivery. In contrast to this 
well-known mechanism, in the proposed technology, the parallelization of flows is performed along the MCN routes [4]. This solution uses the natural redundancy of the network and is, of course, much cheaper. Efficiency of parallelization of flows on several routes $m$ is determined by the formula

$$
\delta=\frac{T_{\text {парал }}}{T_{\text {посл }}} \times 100 \%,
$$

where $T_{\text {посл }}$ - time spent on sequential delivery of a stream of packets by a single route, $T_{\text {парал }}$ - time spent delivering the same stream over multiple routes. $T_{\text {посл }}$ depends on the characteristics of each element $k$ of this route, a $T_{\text {парал }}$ - from the characteristics of the slowest route when dividing the flow by routes, that is

$$
T_{\text {парал }}=\max T_{\text {мари }}^{i}, i=1 . . . m \text {. }
$$

Obviously, the delivery time of the message (stream) will depend on the number of routes used and their performance characteristics.

\section{Model of the error correction mechanism}

Packet replication-reducing packet loss and/or the number of error packets by introducing spatiotemporal packet redundancy. In the node $C_{i}$ copies of the packages are created, and the package and its copies are delivered to the edge node $C_{j}$ different routes from the route subsystem [6]. Replication can be multiples or fractions. Fractional replication implies that for a stream consisting of $m$ packets, copies of the $k$ packets are being created (replication coefficient), at the same time $m<<k$. Obviously, for multiple replication $m=k$. The $m$ packet stream and the $k$ packet copies are routed by different routes.

Fractional replication can be used to ensure the integrity of large-volume streams, for example, video, audio broadcasts, etc.

Multiple replication can be used to deliver packets that make up a small message, when the loss of such a message will lead to disastrous consequences. Such messages can include, for example, command signals to protection devices in power supply systems or command signals of emergency protection systems in nuclear power, periodically transmitted messages in on-board information and control systems, etc.

\section{Methodology for evaluating the effectiveness of the error correction mechanism}

The method of evaluating the effectiveness of the error correction mechanism is based on the use of the mathematical apparatus of graph theory and finding connectivity by a set of routes between graph elements using the method of iterating elementary paths (routes). The structure of the MCN is modeled by the graph of the network, the vertices and edges of which are nodes and communication channels. The vertices of the graph represent the nodes of the network $C \bigcup H$, but edges are communication resources (ij), which connect the vertices of the graph to each other. All elements of the graph (vertices and edges) are assigned a weight coefficient, which is the coefficient of operational readiness of the node and the probability of loss of the packet by the communication resource.

On the constructed MCN graph, two poles are distinguished (two vertices-the boundary nodes "source" and "drain"), which mark the selected direction of data exchange. All elementary paths are selected in the selected direction $m$ between the selected pair of network poles. For all elements of the graph, the connectivity of the two-pole network between the selected nodes is calculated by combining elementary paths, taking into account the absorption effect. The complete list of elementary paths between network nodes is determined based on the maximum allowed number of route elements $k$ (restrictions on the length of the elementary path).

Then the criterion for package delivery is the presence of at least one of several delivery routes, both the package itself and its copies between the considered nodes can be considered (connectivity of routes from the route subsystem). Assume that there is a list of possible delivery routes for a packet and its copies between the source $s$ and the drain $t$ in the form of a list of items included in each route.

The probability of package delivery by anyone $K_{m}$ route, where $m=\|M\|$ is the power of the set of routes between the sending node and the receiving node can be calculated using the serial connection formula $K_{m}=r_{s} \cdot p_{s 2} \cdot r_{2} \cdot p_{23} \cdot \ldots \cdot r_{i} \cdot p_{i j} \cdot \ldots \cdot p_{k t} \cdot r_{t}$, where $r_{i}$ is, in our case, the operational readiness coefficient, $p_{i j}=1-q_{i j}$, and $q_{i j}$ is the probability of packet loss in the $k$-th edge of the route, at the same time $q_{i j}$ thanks to the serial connection formula takes into account both the probability of packet loss due to the reliability characteristics of the edge, and the probability of packet loss due to distortion and network congestion. In this case, the desired probability of delivery of the package $P_{s t}$ depends on the probability of delivery of the package and its copies on each route.

Thus, the probability of packet delivery is correlated with a well-defined probability of connectivity between the routes of the sending node and the receiving node. In general, the routes will be dependent, since any element of the network can be included in different routes. That is $P_{s t}$ it depends on the probability of delivery of the package on each individual route and the options for intersecting these routes on common elements. Denote the probability of package delivery, which is provided by the first routes $i$ from $m$, through $P_{i}, i=1, \ldots, m$. Adding the next one $(i+1)$ route with the probability of delivering a copy of the package $K_{i+1}$ will increase the probability of packet delivery, which will be determined by combining two events: there is at least one route (either of the $i$ first, either of the $(i+1)$-th). The probability of occurrence of this combined event, taking into account the possible dependence of the presence of $(i+1)$ route and the first:

$$
P_{i+1}=P_{i}+K_{i+1}-K_{i+1} P_{i /(i+1)},
$$

where $P_{i /(i+1)}$ - the probability of having at least one of the first 
$i$ routes provided that there is $(i+1)$-th route.

From the definition of conditional probability $P_{i /(i+1)}$ follows that when calculating it, the probability of proper operation of all elements during the passage of the packet and the possibility of losing it due to distortions in these elements included in $(i+1)$-th route, must be put equal to one. For convenience, we present the last term of expression (1) in the following form

$$
K_{i+1} P_{i /(i+1)}=K_{i+1} * P_{i},
$$

where $(*)$-symbolic multiplication operation, which means that when multiplying the probability of packet delivery by each element included in the first $\boldsymbol{i}$ routes and shared with $(i+1)$-th route, are replaced by a unit. Taking into account (2), you can rewrite (1)

$$
\Delta P_{i+1}=K_{i+1} * Q_{i},
$$

where $\Delta P_{i+1}=P_{i+1}-P_{i}$ - increment of the probability of package delivery at the time of introduction $(i+1)$ delivery route of a copy of the package; $Q_{i}=1-P_{i}$ - the probability that there will be a packet loss on the first $i$ routes.

Given that the increment in the probability of delivery $\Delta P_{i+1}$ is numerically equal to the decrease in the probability of loss $\Delta Q_{i+1}$, we obtain the following equation in finite differences:

$$
\Delta Q_{i+1}=K_{i+1} * Q_{i} .
$$

The solution to equation (4) is the function

$$
Q_{i}=\left(1-K_{1}\right) *\left(1-K_{2}\right) * \ldots *\left(1-K_{i}\right) .
$$

From the relations (1) - (5), it is obvious that the increment of the probability of delivery of the packet at the introduction of $(i+1)$ delivery route for a copy of the package $\Delta P_{i+1}$, the more, the less common elements the first ones have $i$ routes with $(i+1)$-th. It follows from this that the greatest effect is from the ratio of the increment of the probability of delivery to the number of routes (copies of packages) $\frac{\Delta P_{i+1}}{m}$ is shown when delivering copies of the package on independent routes.

In the case of independent routes, the symbolic multiplication operation is the same as the usual multiplication, and the expression (5) gives the probability of packet loss between the sending node and the receiving node, since the transmission of the packet and its copies in the network is carried out on routes that do not have common elements

$$
Q_{s t}=\left(1-K_{1}\right) \times\left(1-K_{2}\right) \times \ldots \times\left(1-K_{m}\right)
$$

From the above mathematical relations (1) - (6), it follows that the proposed model of the error correction mechanism allows, with the introduction of the next route for the delivery of copies of the package, to increase the probability of delivery of the package $P_{s t}$ without taking special measures to reduce (adjust) losses on each route.

\section{References}

1. R. Albert, A.-L. Barabasi (2002). Statistical mechanics of complex networks. Reviews of modern physics. 2002. Vol. 74. No. 1. P. 47.

2. D. Krioukov, K. Fall, A. Brady, others (2007). On compact routing for the Internet. ACM SIGCOMM Computer Communication Review. Vol. 37. No. 3. P. 41-52.

3. A. Capone, L. Fratta, F. Martignon (2006). Dynamic online QoS routing schemes: performance and bounds. Computer Networks. No. 50. P. 966-981.

4. A. Capone, L. Fratta, F. Martignon (2003). Dynamic routing of bandwidth guaranteed connections in MPLS networks. Intern. Journal on Wireless \& Optical Communications. No. 1. P. 75-86.

5. V.N. Kudelya (2019).Method of multirouting data blocks in a switched network. Russian Patent No. 2678470.

6. V.N. Kudelya (2012). Method of guaranteed delivery of data blocks in a lossy switched network. Russian Patent No. 2461136. 


\title{
ТЕХНОЛОГИЧЕСКАЯ МОДЕЛЬ И МЕТОДИКА ОЦЕНКИ УСТОЙЧИВОСТИ ФУНКЦИОНИРОВАНИЯ МУЛЬТИСЕРВИСНОЙ СЕТИ СВЯЗИ
}

\author{
Куделя Виктор Николаевич, ЗАО "Институт Сетевых Технологий", г. Санкт-Петербург, Poсcuя, Kudelia.Viktor@int.spb.ru \\ Гель Валентин Эдуардович, Военная академия связи имени Маршала Советского Союза С.М.Буденного, \\ 2. Санкт-Петербург, Россия, gel@rambler.ru \\ Вовк Валерий Васильевич, Главное управление связи ВС РФ, г. Москва, Россия, GUS_I@mil.ru
}

\section{Аннотация}

Современное развитие мультисевисных сетей связи (МСС) характеризуется стремлением операторов к предоставлению пользователям неограниченного спектра услуг с гарантированным качеством обслуживания (Quality of Service, QoS). QoS определяется устойчивостью функционирования сети, то есть её способностью функционировать без ошибок. Существующие алгоритмы маршрутизации в современных сетях основную нагрузку сосредо-тачивают на наиболее производительных участках, при этом остальная часть сети используется довольно слабо. Это подтверждается результатам исследований, в которых структура современных глобальных сетей связи отнесена к классу small-world графов. Очевидно, что повышенная связность таких сетей определяет высокие показатели её устойчивости, но в тоже время эта маршрутная избыточность плохо используется существующими протоколами маршрутизации для обеспечени QoS при передаче разнородного трафика (triple-play: аудио, видео и данные). Так же отсутствуют и работы, посвященные анализу возможностей совместного использования различных маршрутов (маршрутного параллелизма) для реализации механизмов повышения QoS в MCC. В настоящей статье рассматривается технологическая концепция сети с маршрутным параллелизмом в сетях связи, построенных на базе семейства протоколов IP.

Ключевые слова: сеть, устойчивость функционирования, качество обслуживания.

\section{Литература}

I. Albert R. Barabsi A.-L. Statistical mechanics of complex networks // Reviews of modern physics. 2002. T. 74, №I. C. 47.

2. Krioukov D., Fall K., Brady A. u дp. On compact routing for the Internet // ACM SIGCOMM Computer Communication Review. 2007. T. 37, №3.

C. $41-52$.

3. Capone A., Fratta L., Martignon F. Dynamic online QoS routing schemes: performance and bounds // Computer Networks. 2006. № 50. P. 966-98I.

4. Capone A., Fratta L., Martignon F. Dynamic routing of bandwidth guaranteed connections in MPLS networks // Intern. Journal on Wireless \& Optical Communications. 2003. № I. P. 75-86.

5. Куделя В.Н. Способ мультимаршрутизации блоков данных в коммутируемой сети. Патент РФ №2678470. 2019.

6. Куделя В.Н. Способ гарантированной доставки блоков данных в коммутируемой сети с потерями. Патент РФ №246II36. 2012.

Информация об авторах:

Куделя Виктор Николаевич, ведущий специалист, д.т.н., ЗАО "Институт Сетевых Технологий", г. Санкт-Петербург, Россия

Гель Валентин Эдуардович, начальник научно-исследовательского иентра, кандидат военных наук, доцент, ФГКВОУ ВПО "Военная академия связи имени Маршала Советского Союза С.М.Буденного" Министерства обороны Российской Федерации, г. Санкт-Петербург, Россия

Вовк Валерий Васильевич, Главное управление связи ВС РФ, Москва, Россия 